\title{
The emergence of spontaneous activity in neuronal cultures, coherence from noise
}

\author{
Javier G Orlandi ${ }^{*}$, Enric Alvarez-Lacalle ${ }^{2}$, Sara Teller ${ }^{1}$, Jordi Soriano ${ }^{1}$, Jaume Casademunt ${ }^{1}$ \\ From Twenty Second Annual Computational Neuroscience Meeting: CNS*2013 \\ Paris, France. 13-18 July 2013
}

When neurons are grown in vitro and left unperturbed, they create their own network of connections and eventually reach a state where they fire simultaneously in a strikingly regular collective pattern of nearly periodic bursts [1]. Even though the spontaneous activity of neuronal networks is widely recognized as a fundamental problem in neuroscience, the mechanisms governing these bursts of spontaneous activity are not well understood. In neuronal cultures many conflicting views coexist, from burst initiation zones in 1D systems [2], to leading neurons [3] and network interactions [4] amongst others. Here we give new insights on the emergence of spontaneous activity in two-dimensional neuronal cultures and tackle this problem with two complementary approaches.

Using high-speed calcium imaging techniques in cultures derived from cortical neurons of embryonic rat brains, we show that the collective bursts of activity are in fact propagating waves of activity that are locally nucleated. The nucleation develops in specific sites of the cultures that are independent of each other and have a well defined size.

With in silico modelling, we elucidate the origin of the bursting activity in terms of a new phenomenon that we call noise focusing, a fast nucleation mechanism that relies both on detailed network topology and on the neurons' integrate-and-fire dynamics. The phenomenon consists of a selective, highly directional noise amplification mechanism that drives activity avalanches towards a few focal points that act as noise attractors. The resulting scenario challenges common understanding of neuronal cultures while providing a simple physical explanation of all the

\footnotetext{
* Correspondence: orlandi@ecm.ub.edu

'Departament d'Estructura i Constituents de la Matèria, Universitat de Barcelona, 08028 Barcelona, Spain

Full list of author information is available at the end of the article
}

existing data with no appeal to any biological guidance of the network architecture.

\section{Author details \\ ${ }^{1}$ Departament d'Estructura i Constituents de la Matèria, Universitat de Barcelona, 08028 Barcelona, Spain. '2Departament de Física Aplicada EETAC, Universitat Politècnica de Catalunya UPC, 08860 Castelldefels, Spain. \\ Published: 8 July 2013 \\ References \\ 1. Eckmann JP, Feinerman O, Gruendlinger L, Moses E, Soriano J, Tlusty T: The physics of living neural networks. Phys Rep 2007, 449:54-76. \\ 2. Alvarez-Lacalle E, Moses E: Slow and fast pulses in 1-D cultures of excitatory neurons. J Comput Neurosci 2009, 26:475-493. \\ 3. Eckmann JP, Jacobi S, Marom S, Moses E, Zbinden C: Leader neurons in population bursts of 2D living neural networks. New J Phys 2008, 10:015011. \\ 4. Eytan D, Marom S: Dynamics and effective topology underlying synchronization in networks of cortical neurons. J Neurosci 2006, 26:8465-8476.}

doi:10.1186/1471-2202-14-S1-P54

Cite this article as: Orlandi et al:: The emergence of spontaneous activity in neuronal cultures, coherence from noise. BMC Neuroscience 2013 14(Suppl 1):P54.

Submit your next manuscript to BioMed Central and take full advantage of:

- Convenient online submission

- Thorough peer review

- No space constraints or color figure charges

- Immediate publication on acceptance

- Inclusion in PubMed, CAS, Scopus and Google Scholar

- Research which is freely available for redistribution
() Biomed Central 